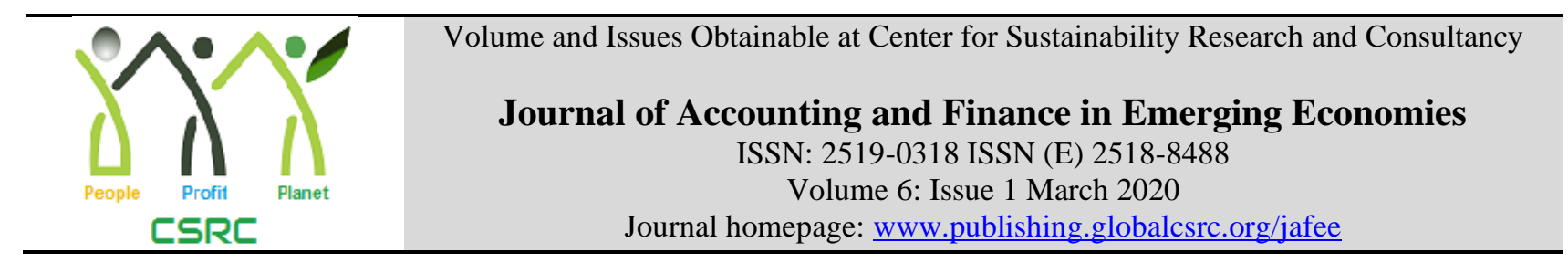

\title{
Testing Market Efficiency, Predictability and Profitability at Pakistan Stock Exchange Using Firm-level Data
}

\author{
${ }^{1}$ Syed Arshad Ali Shah, ${ }^{2}$ Naimat Ullah Khan, ${ }^{3}$ Muhammad Daud Ali \\ ${ }^{1} \mathrm{PhD}$ Scholar at Institute of Management Studies, University of Peshawar Pakistan Email: arshad@bkuc.edu.pk \\ ${ }^{2}$ Assistant Professor at Institute of Management Studies, University of Peshawar ,Pakistan: Email: \\ naimatims@yahoo.com \\ ${ }^{3}$ Assistant Professor Department of Management Sciences, University of Haripur, Pakistan: Email: \\ dr.daud@uoh.edu.pk
}

\begin{tabular}{ll}
\hline \multicolumn{1}{c}{ ARTICLE DETAILS } & ABSTRACT \\
\hline History & This study examines market efficiency in the light of the simple moving \\
Revised format: February 2020 & average technical trading rules on daily closing share prices of 100 \\
Available Online: March 2020 & companies listed on Pakistan Stock Exchange over ten years from 2006 to \\
& 2015. The results show strong support for simple moving average rules \\
having both predictability and profitability for PSX. It refers that the & returns from these rules are not same as investors earn from a naïve buy \\
Simple Moving Average Rules; & and hold strategy. The uses of these simple moving average rules produce \\
Predictability; Nä̈ve Buy and & abnormal returns to investors and hence nullify the weak form of \\
Hold Strategy; Pakistan Stock & efficiency on PSX.
\end{tabular}

Hypothesis

JEL Classification:

G39, L19, M59

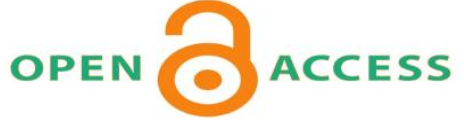

(C) 2020 The authors, under a Creative Commons Attribution-Non

Commercial 4.0

Corresponding author's email address: arshad@bkuc.edu.pk

Recommended citation: Shah, S. A. A., Khan, N. U. \& Ali, M. D., (2020). Testing Market Efficiency, Predictability and Profitability at Pakistan Stock Exchange Using Firm-level Data. Journal of Accounting and Finance in Emerging Economies, 6 (1), 1-10

DOI: $10.26710 /$ jafee.v6i1.1054

\section{Introduction}

Market efficiency and technical trading rules (TTRs) are important for practitioners and researchers to judge the predictability and non-predictability of shares.Technical analysis is assumed to be one of the primary types of investment technique which traces back to the Dow theory, that was established by Charles Dow and further established by William Peter Hamilton in the 1800s. It states that security prices move in definite stages with foreseeable patterns. On the basis of this concept, the prices in moving trends are determined by the shifting behaviour of investors in the direction of a change of political, monetary, psychological, and economic factors. Pring (2002) documented that "the skill of technical technique is to recognize trend deviations at a comparatively initial phase and to uphold an investment 
position up to the weight of signshows that the trend has overturned" (p. 3).

The beliefs of the technical analysis for making investment decisions are based on historical market data. Its purpose is to construct buying and selling rules that maximize the wealth of the stockholders and control the risk of loss. According to the EMH, market follows random walk and investors cannot predict future share returns based on the assumption of past data. Resultantly, the TTRs are futile as they can neither be applied in the predictability nor to earn abnormal profit. If shareholders can make abnormal profit by using these rules it shows that the market is inefficient (Tharavanij, Siraprapasiri, \& Rajchamaha, 2015).

In case of emerging1 financial markets, the study conducted by Bessembinder and Chan (1995) suggested that SMA and TRB are quite useful to forecast profitability in the stock exchnages of Taiwan,Malaysia, and Thailand. The study conducted by Gunasekarage \& Power (2001) in South Asian markets to find out the predictability of TTRs, and the results showed that rules had forecasting power in South Asian financial markets. The present study examines the weak form of market efficiency with the help of TTRs in the capital market of Pakistan. The current study is different from existing literature because it is among the first studies which uses technical trading rules to examine the EMH on the PSX. In addition, this study uses the firm share prices data instead of index data. Simple Moving Average (SMA) rules are applied for technical analysis of the market in this research article. One of the significant findings of this paper is to recommend to the policy makers that the financial market may be given more liberalization in order to reduce the overt reliance on loans. Moreover, the regulatory bodies should focus to enhance the level of access to information and transparency for listed firms on PSX, and also established a policy that educates all the market participants on investment decision making.In addition, this paper may also benefit decision makers who have participated in various aspects of capital market, especially, those studying the efficiency and profitability of SMA rules. Remaining of the paper is as follows: Section 2 is about Review of Literature followed by Section 3 on Methodology; Section 4 shows results and the last Section concludes the study.

\section{Review of Literature}

The financial market of a country plays a very essential part in developing the economic growth (Dsouza and Mallikarunappa, 2015). According to EMH, the stock prices fully reflected relevant information in the market and investors cannot earn abnormal profits on the basis of public or private information of the past (Fama, 1970). Fama (1970), categorized EMH into three forms, i.e., Strong_form of efficiency, Semi-Strong form of efficiency and Weak-form of efficiency. The Weak form of EMH assumes the availability of the previous stock prices, whereas, Semi-strong form of EMH assumes the availability of public information and including past stock prices to all participants. The Strong form of EMH assumes the availability of public and private information to all investors with no information asymmetry (Fama, 1970). This study tests Weak form of EMH with the help of simple moving average rules. It assumes that investors cannot outperform the stock exchange based on past share prices.

However, a number of of the research works confirmed the usefulness of the TTRs in predictability. (Yu, Nartea, Gan, \& Yao, 2013; Metghalchia, Marcucci, \& Chang, 2012; Gunasekarage \& Power (2001); Bessembinder \& Chan, 1995; Brock, Lakonishok \& LeBaron, 1992). Brock et al. (1992) tested TTRs, i.e., Simple Moving Average (SMA) and Trading Range Breakout (TRB) rules and suggested that these rules have the substantial forecasting power in DIJA index of the USA capital market. Another study conducted to investigate the forecasting power of the SMA and TRB rules and found that both the rules had forecasted ability in the Taiwan, Malaysia, and Thailand equity markets, after considering the transaction costs. However, in the financial markets of the more established stock exchangesof Hong Kong and Japan had weak predicting ability(Bessembinder \& Chan, 1995).

1. This paper adopts the definition of emerging markets, which is used by IFC. 
The study conducted by Gunasekarage and Power (2001) to investigated the forecasting power of SMA rules in the four leading South Asian stock exchanges, i.e., Dhaka, Colombo, Bombay and Karachi Stock exchange, using daily index data. The results indicated that the four the markets had the predictable in stock prices. They observed that by using these trading rules the investors could earn excessive returns from the South Asian financial markets. Mitra (2011) studied the predictability and profitability of SMA rules and showed that SMA rules had predictability power the stock prices in the four Indian equity markets. In his study of the market he did not take the transaction cost into account. Finally, he documented that investors could earn excess returns from SMA. Yu, Nartea, Gan, and Yao (2013) took a sample of five leading Southeast Asian markets2, for the time period 1991 to 2008, with the help of SMA and TRB. . The findings suggested that the rules had stronger predicting ability in security price movement in the emerging markets except in the developed market of Singapore. They further suggested that after considering the transaction cost the rules were profitable to some extent in Thailand.

Tharavanij et al., (2015), tested technical trading strategies in five Southeast Asian financial market indices namely, JSX composite index, FTSE Bursa Malaysia KLC index, PSE composite index, FTSE straits time index and SET index, in Indonesia, Malaysia, Philippines, Singapore and Thailand respectively, from 2000 to 2013. They found the predictability of rules in the Thailand, but did not support the developed market of Singapore. These rules also generated abnormal returns in the three stock markets of Indonesian, Malaysian and Philippine. Though, after considering trading costs, maximum of the rules did not produce net returns. Study of Khan, Khan, Hussain, Shah, and Abbas (2017) observed that KSE-100 index is not a weak form efficient. They used data on KSE-100 index and employed various technical analyses such as an exponential and simple moving average rules with the generalized regression neural network. The research conducted by Khan, Aman, and Khan (2016) rejected the random walk hypothesis and claimed that investors can earn abnormal profits. The study of Almujamed, Fifield, and Power (2108) employed the technical trading rules for the forty two firms of Kuwait Stock Exchange and found that the filter rules had predictability power of stock prices in KSE.

The above literature has confirmed that the trading rules are efficient and have predictability in the case of emerging markets as well as developed markets. That implies the essence of the efficiency in these markets. In addition, the above studies use index data for analysis. The uniqueness of the study is the use of daily share prices of 100 firms listed on PSX over the period 2006 to 2015 using SMA rules.

\section{Methodology}

\subsection{Data}

This study uses firm level daily closing share prices of 100 firms listed the PSX. These firms have been chosen on the basis of highest market capitalization since January 2, 2006. The time span covers a ten year from the January, 2006 to December, 2015. The returns for each company are computed as follows:

$$
\mathrm{R}_{\mathrm{it}}=\operatorname{Ln}\left[\left(\mathrm{l}_{\mathrm{it}} / \mathrm{l}_{\mathrm{it}-1}\right)\right]
$$

Where $\mathrm{R}_{\mathrm{it}}$ isthe return on a share $i$ for the day $t$,

$l_{\text {it }}$ is the stock price at time $t$,

$l_{\text {it }-1}$ represents the stock price at time $\mathrm{t}-1$,

Ln denotes the natural logarithm.

This paper opts technical trading rules of SMA, which according to Brock et al., (1992) are the simplest as well as most widely used in such analyses. These rules are used to guage predictability and potential 
profitability. The SMA rules produced buy and sell signals on the basis of movement between short and long run period of share prices. The SMA rules involve buying (selling), when the short run period cross below (above) the long run period. The concept behind the application of the SMA rules is established on the assumption that time series data is unpredictable and may have movements in these series.

SMA rules are further divided in two categories; Variable Length Moving Average (VLMA) and Fixed Length Moving Average (FLMA) rules also known as Variable Moving Average, VMA and Fixed Moving Average, FMA rules. Brock et al., (1992) defined VLMA as, “A buy or sell signal initiates once the short run period cross above (below) the long run period by an amount higher than size of the bandwidth" (pp. 1735-1736). A per this rule, no signal is produced until the short run period is within the bandwidth. This rule suggests a policy where the investors take long position as the short run period moves above the long run period. Moreover, the investors should want in the market till the short run period moves below the long run period which signal for sale. If the band is $0 \%$, this technique categorizes a full day into one or the other buys (sells).

The FLMA rule emphasizes on the crossover of the long run period by the short run period. Brock et al. (1992) define FLMA as "A buy (sell) signal is produced when short run period cross the long run period from above (below)" (p. 1736). The technician presume that returns must be changed for some days after signals are produced. Once a signal is initiated, the investors should stay in the same situation (buy/sell) for at least ten-day period (the study assume ten day study). (Brock et al. (1992). When the stipulated days are lapsed, the rule allows reacting to a new signal.

This study uses the same selection of lengths for short and long run period and the size of bandwidth which is used by Brock et al., (1992). For each VLMA and FLMA rules, the paper evaluates the 10 variation of the rules; $(1,50,0) ;(1,150, .0) ;(5,150,0) ;(1,200,0) ;(2,200,0) ;(1,50, .01) ;(1,150, .01)$; $(5,150, .01) ;(1,200, .01)$ and $(2,200, .01)$. The rules vary from one another with regard to the length of the short run period and long run period and by the size of the bandwidth. In the parentheses, the left figure signifies the number of day's short run period' and the middle figure signifies the number of days in 'long run period' and the right side figure denotes the 'band size'. For example $(1,50,0) 1$ denotes short run period, 50 denotes the long run period and 0 represent the size of bandwidth in percentage.

The Buy and Sell signals are produced as follows:

$$
\begin{gathered}
\sum^{\mathrm{S}} \mathrm{R}_{\mathrm{i}, \mathrm{t}} / \mathrm{S}>(1+\mathrm{X}) \sum^{\mathrm{L}} \mathrm{R}_{\mathrm{i}, \mathrm{t}-\mathrm{l}} / \mathrm{L}=\text { Buy } \\
\text { AND } \sum^{\mathrm{S}} \mathrm{R}_{\mathrm{i}, \mathrm{t}} / \mathrm{S}<(1+\mathrm{X}) \sum^{\mathrm{L}} \mathrm{R}_{\mathrm{i}, \mathrm{t}-1} / \mathrm{L}=\text { Sell } \\
\mathrm{R}_{\mathrm{i}, \mathrm{t}}=\left(\mathrm{P}_{\mathrm{i}, \mathrm{t}}-\mathrm{P}_{\mathrm{i}, \mathrm{t}-1}\right) / \mathrm{P}_{\mathrm{i}, \mathrm{t}-1}, \quad(\text { and } \mathrm{X}=0 \% \text { and } 1 \%)
\end{gathered}
$$

Where $\mathrm{R}_{\mathrm{i}, \mathrm{t}}$ is the daily return of the PSX in the short run period $\mathrm{S}$ (1,2 or 5 days); $\mathrm{R}_{\mathrm{i}, \mathrm{t}-1}$ is the daily return of the PSX in the long run period L (50,150 or 200 days);

$\mathrm{P}_{\mathrm{i}, \mathrm{t}}$ is the daily closing prices PSX at time $\mathrm{t}$ And $\mathrm{X}$ is the percentage of band zero and one percent respectively.

This method is reiterated each trading day within order to take account of a constant shifting, moving average of the last $\mathrm{N}$ days. For VLMA rules, the buy position is held until the sell signal is initiated by the above equation 2 :

\subsection{Conditions for Predication for VLMA and FLMA Rules}

According to Hudson et al. (1996), if a financial market follows the following conditions for VLMA and FLMA rules, then we are saying this particular financial market has the predictive ability. 
1. If thenumber of signals for the buy is similar to the number of sell signals for both rules.

2. If the buy generate positive mean (return) and sell generate negative mean (return) for both rules.

3. If the buy and sell mean is considerably different from the unconditional mean of one day for VLMA and ten days for FLMA rules.

4. The profit can be earned from VLMA rules when the length of long period is increased similarly for FLMA.

\section{Results and Discussions}

Table 1 refers the summary statistics of the ten years for daily (Panel A) and ten days returns (Panel B). Panel A shows the results of one day return, which is used for comparison the result of VLMA method. One day mean return of 0.089 percent is reported by sample firms. The standard deviation of returns resulted to be 2.04 percent as per our analysis. The panel B reports 10-day returns, which is calculated for the purpose of comparing with the finding of FLMA.

Table 1 panel A: Basic statistics of daily return of PSX.

\begin{tabular}{|l|l|l|l|}
\hline \multicolumn{2}{|l|}{ Panel A (Average Daily) } & \multicolumn{2}{l|}{ Panel B (Average 10 days) } \\
\hline Mean & St.Dev & Mean & St.Dev \\
\hline 0.000890 & 0.020447 & 0.001801 & 0.019521 \\
\hline
\end{tabular}

\begin{tabular}{|c|c|c|c|c|c|c|c|c|}
\hline 1 & 2 & 3 & 4 & 5 & 6 & 7 & 8 & 9 \\
\hline PERIOD & Rules & N.BUYS & N.SELLS & $\begin{array}{l}\text { BUY } \\
\text { Mean }\end{array}$ & $\begin{array}{l}\text { SELL } \\
\text { Mean }\end{array}$ & Buy > 0 & Sell > 0 & Buy -Sell \\
\hline \multirow[t]{2}{*}{ 2006-2015 } & $(1,50,0)$ & 49294 & 49279 & 0.00718 & -0.00719 & 0.022590 & 0.002563 & $\mathbf{0 . 0 1 4 3 7 0}$ \\
\hline & & & & $(33.93259)$ & $(-33.89455)$ & & & $(52.296130)$ \\
\hline \multirow[t]{2}{*}{ 2006-2015 } & $(1,50, .01)$ & 49276 & 49261 & 0.00718 & -0.00718 & 0.022603 & 0.002572 & 0.014360 \\
\hline & & & & $(33.91998)$ & $(-33.88195)$ & & & $(52.275160)$ \\
\hline \multirow[t]{2}{*}{$2006-2015$} & $(1,150,0)$ & 49021 & 49012 & 0.00725 & -0.00726 & 0.022353 & 0.001662 & $\mathbf{0 . 0 1 4 5 1 0}$ \\
\hline & & & & $(34.18826)$ & $(-34.14752)$ & & & $(52.666900)$ \\
\hline \multirow[t]{2}{*}{ 2006-2015 } & $(1,150, .01)$ & 49008 & 48999 & 0.00725 & -0.00726 & 0.022364 & 0.001682 & 0.014510 \\
\hline & & & & $(34.17818)$ & $(-34.13744)$ & & & $(52.650323)$ \\
\hline \multirow[t]{2}{*}{ 2006-2015 } & $(5,150,0)$ & 22299 & 22286 & 0.00377 & -0.00378 & 0.024660 & 0.015246 & 0.007550 \\
\hline & & & & $(12.54751)$ & $(-12.51718)$ & & & (18.465496) \\
\hline \multirow[t]{2}{*}{$2006-2015$} & $(5,150, .01)$ & 22303 & 22291 & 0.00376 & -0.00377 & 0.024656 & 0.015261 & $\mathbf{0 . 0 0 7 5 3 0}$ \\
\hline & & & & $(12.53942)$ & $(-12.5095)$ & & & $(18.454029)$ \\
\hline \multirow[t]{2}{*}{ 2006-2015 } & $(1,200,0)$ & 48933 & 48923 & 0.00726 & -0.00727 & 0.022285 & 0.001507 & $\mathbf{0 . 0 1 4 5 3 0}$ \\
\hline & & & & (34.19811) & $(-34.15944)$ & & & $(52.676990)$ \\
\hline \multirow[t]{2}{*}{ 2006-2015 } & $(1,200, .01)$ & 48919 & 48909 & 0.00726 & -0.00727 & 0.022294 & 0.001518 & $\mathbf{0 . 0 1 4 5 3 0}$ \\
\hline & & & & (34.18973) & $(-34.15108)$ & & & $(52.662905)$ \\
\hline \multirow[t]{2}{*}{ 2006-2015 } & $(2,200,0)$ & 34695 & 34683 & 0.00558 & -0.00558 & 0.024661 & 0.010909 & 0.011160 \\
\hline & & & & $(22.65661)$ & $(-22.62236)$ & & & $(34.080669)$ \\
\hline \multirow[t]{2}{*}{$2006-2015$} & $(2,200, .01)$ & 34677 & 34665 & 0.00557 & -0.00558 & 0.024666 & 0.010909 & $\mathbf{0 . 0 1 1 1 5 0}$ \\
\hline & & & & $(22.64373)$ & $(-22.61237)$ & & & $(34.062132)$ \\
\hline AVERAGE & & & & 0.006206 & -0.006214 & & & 0.012420 \\
\hline
\end{tabular}

The table shows the descriptive statistics of the PSX over the period of 10 years (2006-2015). The mean presents the equally weighted average of the daily and ten days observations over the 10- years. Std.Dev, present the standard deviation of the daily and ten day returns. 
The number marked with * is significant at $1 \%$ level

\subsection{Results of VLMA Rules}

Table 2:

The Table 2 shows the results of 10 VLMA rules for the PSX, from 2006-2015, with zero and one percent band. Column 1 of the Table 2 refers the period, the column 2 shows the rules, whereas 3 and 4 columns shows the days of buy and sell signals for the various rules. Similarly, 5 and 6 columns shows the daily mean returns throughout buy and sell duration by corresponding $t$-statistics given in the same column in parentheses testing the quality of the corresponding returns with unconditional mean daily returns. The 7 shows a fraction of buys and 8 shows a fraction of sell signals. The averages across 10 rules are shown in the 9column of the Table, where the Value of $t$ test is shows in parentheses and calculated with: $\mu_{\mathrm{p}}-\mu_{\mathrm{t}} /\left(\sigma^{2} / \mathrm{M}_{\mathrm{p}}+\sigma^{2} / \mathrm{M}_{\mathrm{t}}\right)^{1 / 2} 3$.

The Table 2 shows the numbers of sell signal is marginally lower than buy signal in all ten rules. The findings do not offer a strong support for the view that the PSX has been bullish trend over the period because the numbers of buy signal are slightly increase than sell signals (Table 2). The 5 and 6 columns show the mean of buy and sell returns. The buy mean returns are positive for all rules with an average 1day mean return of $0.62 \%$, which is almost $16 \% 4$ at an annual return rate; the amount is close to the value reported by Hudson et al. (1996) and Brock et al. (1992). Using two tailed test at $1 \%$ significance level, all the ten tests for both buy and sell, reject the null hypothesis as the return is equal to unconditional returns, $0.089 \%$ is the unconditional one-day return (reported Table 2). The rules (1, 200, 0 ) are the top performing rule with the maximum mean returns and t-values amongst all ten rules as per as the buying side is concerned. While all sell mean returns are negative for all rules with an average 1-day mean return of $-0.62 \%$, which is almost $-16 \% 5$ at an annual return rate. The $t$-test is highly significant for all sell mean returns. Whereas, the sell side, again, the rules $(1,200,0)$ are the top performing rule with the maximum mean returns and t-values amongst all described rules. Its refers that investors can earn maximum return if it stays for one day in short run and 200 days in the long run with zero percent band. All the mean values of buy and sell are highly significant. In the above discussion, it is shown that PSX met the first three conditions of predictability and it also shows that a weak form of efficiency does not exit.

The value of the fraction of buys is larger than zero and the value of fraction of sells is higher than zero which is shown in columns 7 and 8 respectively. The range of the fraction for buys lies between 0.022 to $0.024 \%$, and it ranges between 0.010 to $0.015 \%$ for sells. The useful (abnormal returns) signals for the fraction is generated when the fraction of positive returns is equal for both. The findings show that both buys and sell signals are not equal which suggests that the rules do not produce useful signals.

This finding is same to Brock et al. (1992). The t-test is highly significant and rejects the null hypothesis of equality. The 9 column reports the differences between the mean daily buy returns and sell returns. The difference of buy mean returns and sell mean returns is positive and significant; we reject the null hypothesis of equality with zero. The overall findings are same to the results of Brock et al. (1992; Fifield;Power and Knipe, 2008; Yu et al., 2013). It has also been observed that in case of PSX, the introduction of $1 \%$ band in every rule do not significantly enhance the spread between sell and buy returns. This result clearly rejects the null hypothesis that profits to be received from VLMA rules are same as those attained from 1 day unconditional return, therefore, offer degrees of forecasting ability in the Pakistan Stock Exchange Gunasekaraged and Power (2001).

A comparison of various results in the Table 2 shows that the profit earned from the VLMA rules slightly

$3 \mu_{\mathrm{p}}$ and $\mathrm{M}_{\mathrm{p}}$ are the mean and number of buys signals and $\mu_{\mathrm{t}}$, and $\mathrm{M}_{\mathrm{s}}$, are the mean and number of sell signals for, $\sigma^{2}$ is the estimated variance for the total sample.

4260 days are taking for trading.

5The negative sign does not mean losses; instead it's only show downward trend, that why we calculated the return. 
raises when the length of the long run period is increased. For instance, the long run period is calculated over a number of days varying from 50 to 200; the results of buy-sell profit increased from 0.014 to 0.015 . Furthermore, in the case of the short run period the profit drops from the difference between buy and sell when the length of the short run enhances. For example, as the number of short -run days increased from $(1,200,0)$ to $(2,200,0)$ the profit drops from 0.014 to 0.011 . Lastly, the highest profit is earned by the largest band of $1 \%$, which generates a fewer number of signals. It's also confirmed that PSX has offered abnormal returns to investors because it meets the last condition.

The analysis of various trading strategies shows that increase in short and long period and bandwidth can lead to increase in profitability in comparison of the naïve buy and hold strategy.

\subsection{Result of FLMA Rules}

Table 3:

\begin{tabular}{|c|c|c|c|c|c|c|c|c|}
\hline $\mathbf{1}$ & $\mathbf{2}$ & $\mathbf{3}$ & $\mathbf{4}$ & $\mathbf{5}$ & $\mathbf{6}$ & $\mathbf{7}$ & $\mathbf{8}$ & $\mathbf{9}$ \\
\hline PERIOD & Rules & N.BUYS & N.SELLS & $\begin{array}{c}\text { BUY } \\
\text { Mean }\end{array}$ & $\begin{array}{c}\text { SELL } \\
\text { Mean }\end{array}$ & Buy > 0 & Sell > 0 & Buy -Sell \\
\hline $2006-2015$ & $(1,50,0)$ & 10494 & 10494 & 0.002173 & -0.00208 & 0.021620 & 0.020440 & $\mathbf{0 . 0 0 4 2 5 3}$ \\
\hline & & & & $(5.07724)$ & $(-4.82581)$ & & & $(7.141991)$ \\
\hline $2006-2015$ & $(1,50, .01)$ & 10491 & 10491 & 0.002174 & -0.00207 & 0.021616 & 0.020453 & $\mathbf{0 . 0 0 4 2 4 4}$ \\
\hline & & & & $(5.08026)$ & $(-4.81340)$ & & & $(7.135173)$ \\
\hline $2006-2015$ & $(1,150,0)$ & 10424 & 10425 & 0.002305 & -0.00208 & 0.021586 & 0.020406 & $\mathbf{0 . 0 0 4 3 8 5}$ \\
\hline & & & & $(5.36867)$ & $(-4.81848)$ & & & $(7.346002)$ \\
\hline $2006-2015$ & $(1,150, .01)$ & 10424 & 10425 & 0.002302 & -0.00207 & 0.021584 & 0.020416 & $\mathbf{0 . 0 0 4 3 7 2}$ \\
\hline & & & & $(5.36317)$ & $(-4.79493)$ & & & $(7.325053)$ \\
\hline $2006-2015$ & $(5,150,0)$ & 9297 & 9297 & 0.001565 & -0.00157 & 0.022039 & 0.020433 & $\mathbf{0 . 0 0 3 1 3 5}$ \\
\hline & & & & $(3.45557)$ & $(-3.42959)$ & & & $(4.954588)$ \\
\hline $2006-2015$ & $(5,150, .01)$ & 9295 & 9295 & 0.001571 & -0.00155 & 0.022063 & 0.020430 & $\mathbf{0 . 0 0 3 1 2 1}$ \\
\hline & & & & $(3.46809)$ & $(-3.38611)$ & & & $(4.932296)$ \\
\hline $2006-2015$ & $(1,200,0)$ & 10391 & 10391 & 0.002392 & -0.00224 & 0.021480 & 0.020536 & $\mathbf{0 . 0 0 4 6 3 2}$ \\
\hline & & & & $(5.56162)$ & $(-5.17439)$ & & & $(7.741326)$ \\
\hline $2006-2015$ & $(1,200, .01)$ & 10391 & 10391 & 0.002392 & -0.00224 & 0.214740 & 0.020538 & $\mathbf{0 . 0 0 4 6 3 2}$ \\
\hline & & & & $(5.56186)$ & $(-5.16835)$ & & & $(7.737146)$ \\
\hline $2006-2015$ & $(2,200,0)$ & 10109 & 10109 & 0.002035 & -0.002 & 0.021999 & 0.020275 & $\mathbf{0 . 0 0 4 0 3 5}$ \\
\hline & & & & $(4.67079)$ & $(-4.55674)$ & & & $(6.650155)$ \\
\hline $2006-2015$ & $(2,200, .01)$ & 10110 & 10110 & 0.002037 & -0.002 & 0.022002 & 0.020283 & $\mathbf{0 . 0 0 4 0 3 7}$ \\
\hline & & & & $(4.67738)$ & $(-4.55427)$ & & & $(6.653141)$ \\
\hline AVERAGE & & & & $\mathbf{0 . 0 0 2 0 9 4 6}$ & $\mathbf{- 0 . 0 0 1 9 9}$ & & & $\mathbf{0 . 0 0 4 0 8 5}$ \\
\hline
\end{tabular}

The Table 3 shows the results of 10 FLMA rules for the PSX, over the period 2006-2015, with zero and one percent band. Column 1 of the Table 2 refers the period, the column 2 shows the rules, whereas 3 and 4 columns shows the days of buy and sell signals for the various rules. Similarly, 5 and 6 columns shows the daily mean returns throughout buy and sell duration by corresponding $t$-statistics given in the same column in parentheses testing the quality of the corresponding returns with unconditional mean daily returns. The 7 shows a fraction of buys and 8 shows a fraction of sell signals. The averages across 10 rules are shown in the 9 column of the Table, where the Value of t-test is shown in parentheses and calculated with $\left(\mu_{\mathrm{p}}-\mu_{\mathrm{t}} /\left(\sigma^{2} / \mathrm{M}_{\mathrm{p}}+\sigma^{2} / \mathrm{M}_{\mathrm{t}}\right)^{1 / 2}\right)$.

The Table 3 shows the number of buy signals is similar to the number of sell signals except the rules of 
$(1,150,0)$ and $(1,150, .01)$. The findings do not offer a strong support for the view that PSX has been a bearish trend over the period because the number of sell signals are slightly increased in buy signals.

The mean returns of buy and sell are described in 5 and 6 columns. The buy mean return of ten rules is positive. The average returns (i.e., 20\%) are larger than the unconditional mean ten-day return (i.e., 18\% as reported in panel B Table 1). It implies that the investor can predict the share prices and can earn abnormal returns; it's also referring that a weak form of efficiency does not exit. Similarly, the average of sell mean (i.e.,-19\%) lower than unconditional mean ten-day return (i.e., 18\%). For all rules of both buy and sell, we reject the null hypothesis that returns are same to ten-day unconditional returns by using two tailed test at 1\% significance level (Brock et al., 1992) and (Hudson et al., 1996). In addition, findings are highly statistically significant for all buy and sell mean to individual rules. The 7 and 8 columns represent buys and sells fraction which are larger than zero. The useful (abnormal returns) signal for the fraction is generated when the fraction of positive returns is equal for thesells andbuys. The results show that both buys and sell signals are not equal which refers to the fact that trading rules do not generate useful signals (Brock et al. 1992).

The overall findings are same to the Hudson et al. (1996). The results show that guarantees the predictive ability in PSX.A general conclusion of FLMA rules which emerged from the result of this research, established that FLMA rules guarantees the predictive ability in Pakistan Stock Exchange. The buy and sell have similar number of signals. Buy signal produces (+ve) returns and sell signals produces (-ve) returns. On average, this is considerablyaltered from the returns of ten days unconditional returns.

The column 9, delineates the differences between the mean daily buy returns and sell returns. The difference between buy mean returns and sell returns is positive and significant, which reject the null hypothesis of equality with zero. The overall findings are alike to the results of Brock et al. 1992; Fifield;Power and Knipe, 2008; Yu et al., 2013). It has also been observed that in case of PSX the introduction of $1 \%$ band in every rule, do not significantly enhanced the spread between sell andbuy returns. This result clearly rejects the null hypothesis that profits to be generated from FLMArules are same as those attained from ten-day unconditional return, therefore, they offer degrees of forecasting ability in the Pakistan Stock Exchange Gunasekaraged and Power (2001). A comparison of various results in the Table 3 shows that the profit earned from the FLMA rules raises slightly, when the length of the long run period is increased. For instance, the long run moving average is calculated over a number of days which differ from 50 to 200, the results of buy-sell profit increased from 0.0031 to 0.0046 . Furthermore, in the case of the short run period; the returndrops from buy-sell when the length of the short run enhances. For example, as the number of short -run days increased from $(1,200,0)$ to $(2,200,0)$ that profit drops from 0.0046to 0.0041. Lastly, the highest profit is earned by the largest band of $1 \%$, which generates a fewer number of signals. It's also confirmed that PSX has offered abnormal returns to investors because it meet the last condition.

\section{Conclusion}

This article investigates the predictability, profitability of the TTRs (applying the SMA rules) and its implication for testing weak form of efficiency on the PSX. The finding of the VLAM and FLMA rules show that stock returns in PSX are predictable because the days of buy signals are same to sell signals. The buy mean returns of ten rules are positive and the null hypothesis that the mean returns from buy is same to unconditional returns in both VLAM and FLAM is rejected; the same results are for sell mean returns. In addition, the findings of the study also confirm that the investors can earn abnormal profit from the VLAM and FLMA rules because the increased length of long run resulted an excess profit for both rules. The study also confirms that there is no trend (i.e., bullish/ bearish) in the PSX as both rules generate same signals to buy and sell. Moreover, VLMA and FLMA rules have beaten the buy and hold strategy in the PSX. The results also recommend that PSX is not a weak form of efficient. Finally, SMA rules prove that the traders can earn the excess profits on the PSX using technical trading rules. 


\section{References}

Almujamed, H. I., Fifield, S. G., \& Power, D. M. (2018). An investigation of the weak form of the efficient markets hypothesis for the Kuwait stock exchange. Journal of EmergingMarketFinance, 17(1), 1-28.

Bessembinder, H., \& Chan, K. (1995). The profitability of technical trading rules in the Asian stock markets. Pacific-Basin Finance Journal, 3(2-3), 257-284.

Brock, W., Lakonishok, J., \& LeBaron, B. (1992). Simple technical trading rules and the stochastic properties of stock returns. The Journal of finance, 47(5), 1731-1764.

Copeland, T. Weston, J. E. and Shastri, K., (2005), Financial Theory and Corporate Policy, 4th Edition, Pearson, Wokingham.

Fama, E.F. (1970). Efficient Capital Markets: A Review of Theory and Empirical Work. The Journal of Finance, 25, 2, 383-417.

Fifield, S. G. M., Power, D. M. and Knipe, D. G. S., (2008), “The Performance of Moving Average Rules in Emerging Stock Markets", Applied Financial Economics,18(19), 1515-1532.

Gunasekarage, A., \& Power, D. M. (2001). The profitability of moving average trading rules in South Asian stock markets. Emerging Markets Review, 2(1), 17-33.

Hudson, R., Dempsey, M., \& Keasey, K. (1996). A note on the weak form efficiency of capital markets: The application of simple technical trading rules to UK stock prices-1935 to 1994. Journal of Banking and Finance, 20(6), 1121-1132.

Khan, M. A., Khan, N., Hussain, J., Shah, N. H., \& Abbas, Q. (2017). Validity of Technical Analysis Indicators: A Case of KSE-100 Index. Abasyn University Journal of Social Sciences, 10(1).

Khan, M. A., Khan, N., Hussain, J., \& Shah, N. H. (2016). Technical Analysis: Concept or $\quad$ Reality? Pakistan Business Review, 18(3), 732-751.

Mallikarjunappa, T., \& Jyothi Dsouza, J. (2014). A Study of Quarterly Earnings Announcement and Stock Price Reactions. IUP Journal of Applied Finance, 20(4)

Metghalchi, M., Marcucci, J., \& Chang, Y. H. (2012). Are moving average trading rules profitable? Evidence from the European stock markets. Applied Economics, 44(12), 1539-1559.

Mitra, S. K. (2011). How rewarding is technical analysis in the Indian stock market?. Quantitative Finance, 11(2), 287-297.

Pring, M. J. (2002). Study Guide for Technical Analysis Explained. McGraw-Hill.

Tharavanij, P., Siraprapasiri, V., \& Rajchamaha, K. (2015). Performance of technical trading rules: evidence from Southeast Asian stock markets. SpringerPlus, 4(1), 552.

Yu, H., Nartea, G. V., Gan, C., \& Yao, L. J. (2013). Predictive ability and profitability of simple technical trading rules: Recent evidence from Southeast Asian stock markets. International Review of Economics \& Finance, 25, 356-371. 
